\title{
Cold and Dense Plasma Sheet Caused by Solar Wind Entry: Direct Evidence
}

\author{
Yue Yu ${ }^{1,2}$, Zuzheng Chen ${ }^{1,2, *}$ and Fang Chen ${ }^{1,2}$ \\ 1 School of Space and Environment, Beihang University, Beijing 100089, China; yu_yue@buaa.edu.cn (Y.Y.); \\ chenys1012@buaa.edu.cn (F.C.) \\ 2 Key Laboratory of Space Environment Monitoring and Information Processing, \\ Ministry of Industry and Information Technology, Beijing 100089, China \\ * Correspondence: zzchen_15@buaa.edu.cn
}

Received: 12 June 2020; Accepted: 2 August 2020; Published: 7 August 2020

check for updates

\begin{abstract}
We present a coordinated observation with the Magnetospheric Multiscale (MMS) mission, located in the Earth's magnetotail plasma sheet, and the Acceleration, Reconnection, Turbulence, and Electrodynamics of the Moon's Interaction with the Sun (ARTEMIS) mission, located in the solar wind, in order to understand the formation mechanism of the cold and dense plasma sheet (CDPS). MMS detected two CDPSs composed of two ion populations with different energies, where the energy of the cold ion population is the same as that of the solar wind measured by ARTEMIS. This feature directly indicates that the CDPSs are caused by the solar wind entry. In addition, $\mathrm{He}^{+}$was observed in the CDPSs. The plasma density in these two CDPSs are $\sim 1.8 \mathrm{~cm}^{-3}$ and $\sim 10 \mathrm{~cm}^{-3}$, respectively, roughly 4-30 times the average value of a plasma sheet. We performed a cross-correlation analysis on the ion density of the CDPS and the solar wind, and we found that it takes 3.7-5.9 $\mathrm{h}$ for the solar wind to enter the plasma sheet. Such a coordinated observation confirms the previous speculation based on single-spacecraft measurements.
\end{abstract}

Keywords: cold and dense plasma sheet; solar wind entry; coordinated MMS/ARTEMIS observation

\section{Introduction}

The Earth's magnetotail plasma sheet, which plays a crucial role in the solar wind-magnetosphere coupling, is usually characterized by hot $\left(\mathrm{T}_{\mathrm{i}} \approx 4 \mathrm{keV}\right)$ and tenuous $\left(\mathrm{N}_{\mathrm{i}} \approx 0.3 \mathrm{~cm}^{-3}\right)$ ions [1]. However, prolonged northward interplanetary magnetic field (IMF) conditions can lead to the formation of rare cold and dense plasma sheets (CDPSs) [2-12]. In the CDPS, the ion number density $\left(>1 \mathrm{~cm}^{-3}\right)$ is several times the typical value of a plasma sheet, while the ion temperature $(\sim 1 \mathrm{keV})$ is lower than the typical value of a plasma sheet.

The CDPS plays crucial roles in the magnetospheric dynamic processes by causing the following consequences. The CDPS probably makes great contributions to the production of storm-time energetic particles [13] and can lead to stronger ring currents during the main phase of storms [9,14]. The CDPS can also lead to the mass loading of the magnetotail. Therefore, it may have effects on substorms [13,15-17] and reduce the reconnection rate $[18,19]$. In addition, by altering the plasma density gradients near the dipolarization fronts (DFs), the CDPS can affect the DF dynamics [20], such as the density-driven instabilities [21,22] and electric field structure [23] near the DFs. Meanwhile, since cold electrons behind the DFs cannot be efficiently accelerated by the Fermi and Betatron acceleration mechanism [24-31], the electron distribution behind the DFs [32-34] may be influenced.

The formation mechanism of the CDPS has been widely studied. The ionosphere and the solar wind were believed to be possible sources of plasma in the CDPS [13,35]. Large plasma temperature anisotropy, caused by the decrease in parallel temperature in a CDPS, indicates the presence of cold and 
field-aligned ionospheric origin ion populations [36]. However, it has been found that the ionospheric outflow is strong during the southward IMF period [37,38], which is inconsistent with the observation that the CDPS is caused by prolonged northward IMF periods. In addition, there is a lack of cold $\mathrm{O}^{+}$ component in the CDPS $[39,40]$. Therefore, the ionosphere may not be the primary source of plasma in the CDPS. Terasawa et al. [10] presented that the plasma density and temperature in the CDPS correlate with those in the solar wind during the northward IMF period, indicating that the solar wind is the source of plasma in the CDPS. In addition, cold ions (e.g., $\mathrm{H}^{+}$and $\mathrm{He}^{2+}$ ) with a lower solar-wind-like energy were widely observed in the CDPS [4,5,41]. Fujimoto et al. [2] found that two ion populations with distinctly different energies coexist in a CDPS, with these lower energy ions being similar to those in the magnetosheath. However, there has been no simultaneous observation of the plasma energy spectrum in both the solar wind and the CDPS. Therefore, there is no direct comparison between the energy of cold ion populations in the CDPS and the energy of ions in the solar wind.

To verify the ion energy of these two populations, two satellites located, respectively, in the plasma sheet and the solar wind should be used. With the launch of the Magnetospheric Multiscale (MMS) mission [42-44], which frequently travelled to the Earth's magnetotail plasma sheet during the summer (May-September) of 2017, and the Acceleration, Reconnection, Turbulence, and Electrodynamics of the Moon's Interaction with the Sun (ARTEMIS) mission [45], which travelled around the Moon and was certainly frequently located in the solar wind, we are able to investigate this issue.

In this study, based on coordinated MMS/ARTEMIS observations, we present two CDPS events in order to provide direct evidence that the CDPS is a consequence of solar wind entry.

\section{Observations}

For the plasma sheet measurements, we use the MMS mission [42]. Specifically, the magnetic field data with a $0.0625 \mathrm{~s}$ resolution are from Fluxgate Magnetometer (FGM) [43], and the plasma data with a $4.4 \mathrm{~s}$ resolution are from Fast Plasma Investigation Instrument (FPI) [44]. For the solar wind measurements, we use the ARTEMIS mission [45]. Specifically, magnetic field data with a $4.3 \mathrm{~s}$ resolution and plasma data with a $4.3 \mathrm{~s}$ resolution are from Fluxgate Magnetometer (FGM) [46] and Electrostatic analyzers (ESA) [47], respectively. All the data are shown in Geocentric Solar Magnetospheric (GSM) coordinates unless noted otherwise.

We present two cold and dense plasma sheet (CDPS) events detected by MMS, when ARTEMIS was in the solar wind. Therefore, a direct comparison of the ion energy spectrum between the plasma sheet and the solar wind can be obtained.

Specifically, the first event was observed by MMS from 10:10:00UT to 11:50:00 UT on 20 July 2017, when MMS spacecrafts were moving from $(-21.655,6.838,4.078) R_{E}$ to $(-22.151,6.636,4.273) R_{E}$ (Earth radii) in Geocentric Solar Magnetospheric (GSM) coordinates (see red pentagram in Figure 1), indicating that MMS spacecrafts were located on the dusk-side of the magnetotail. At the same time, ARTEMIS was moving from $(42.503,-40.308,-5.009) R_{E}$ to $(42.813,-39.733,-5.006) R_{E}$ in GSM coordinates (see yellow pentagram in Figure 1), indicating that ARTEMIS was located in the solar wind. 


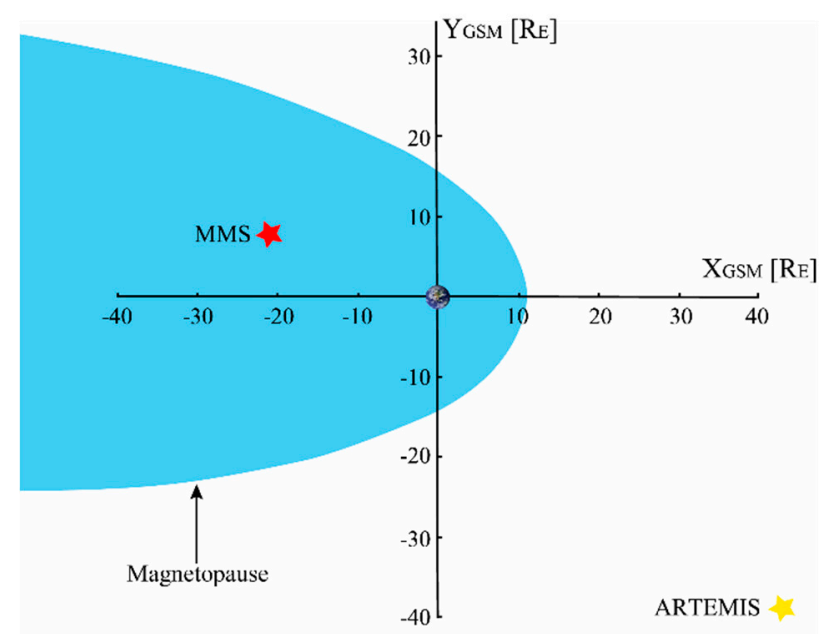

Figure 1. The locations of MMS (denoted by red pentagram) and ARTEMIS (denoted by yellow pentagram) in the GSM coordinates on 20 July 2017. The cyan grid region denotes the magnetosphere. The location of the magnetopause is calculated with Sibeck's model [48]. GSM = Geocentric Solar Magnetospheric.

Figure 2 presents an overview of the event, with the magnetic field shown in panel a, the ion and electron number density in panel $b$, electron temperature in panel $c$, ion temperature in panel $\mathrm{d}, \mathrm{T}_{\mathrm{i}} / \mathrm{T}_{\mathrm{e}}$ in panel e, ion velocity in panel $\mathrm{f}$, pitch angle distribution of $2-200 \mathrm{eV}$ electrons in panel $\mathrm{g}$, ion differential energy flux $(0.01-30 \mathrm{keV})$ in panel $\mathrm{h}$, and plasma $\beta$ in panel $i$. These data were collected by MMS1 in the fast mode [42]. During this period, MMS measured a small magnetic field $\mathrm{B}_{\mathrm{x}}\left(\left|\mathrm{B}_{\mathrm{x}}\right|<20 \mathrm{nT}\right.$; see blue line in Figure 2a), high plasma densities $\left(\mathrm{N} \gtrsim 1 \mathrm{~cm}^{-3}\right.$; Figure $\left.2 \mathrm{~b}\right)$, and large plasma $\beta$ ( $\beta>0.5$; Figure 2i), indicating that it was in the plasma sheet [49]. After 11:40:00 UT, two DFs (Figure 2a), characterized by a sharp increase in the Z-component of the magnetic field [24,50], were detected in a flow burst (Figure 2f) [49]. At the beginning (before 10:30:00 UT) and the end (after 11:30:00) of this interval, the plasma number density $\left(1-2.2 \mathrm{~cm}^{-3}\right.$; Figure $\left.2 b\right)$ is higher than the average in the plasma sheet $\left(\sim 0.3 \mathrm{~cm}^{-3}[1]\right)$, while both the ion (1-1.8 keV; Figure $\left.2 \mathrm{~d}\right)$ and electron temperature (130-230 eV; Figure 2c) are lower than the average in the plasma sheet $\left(\mathrm{T}_{\mathrm{i}} \sim 3 \mathrm{keV}, \mathrm{Te} \sim\right.$ $500 \mathrm{eV}$ [1]). Between 10:30:00 UT and 11:30:00, the plasma density rapidly increases from $1.4 \mathrm{~cm}^{-3}$ to $1.8 \mathrm{~cm}^{-3}$ (Figure $2 \mathrm{~b}$ ), i.e., $4.5-6$ times the average of the plasma sheet. In addition, the ion and electron temperatures decrease to $\sim 800 \mathrm{eV}$ (Figure 2d) and $\sim 100 \mathrm{eV}$ (Figure 2c), respectively. The ion spectrum features two ion populations with distinctly different energies (Figure $2 \mathrm{~h}$ ), whose cold and hot ion population energies are $\sim 1 \mathrm{keV}$ and $\sim 3 \mathrm{keV}$, respectively. These features are consistent with those in the CDPS $[10,35,51-54]$, which is widely believed to be the consequence of the solar wind entry [12,51,52]. During the crossing of the CDPS (10:10:00-11:50:00 UT), the temperature of the cold ion populations was $\sim 400 \mathrm{eV}$ (green curve in Figure $2 \mathrm{~d}$ ), while that of the hot ion populations was $\sim 11,500 \mathrm{eV}$ (blue curve in Figure 2d). As can be seen, the ratios of the ion to electron temperature and cold ion to electron temperature were $\sim 9$ and $\sim 4$, respectively. In addition, these electrons with a low energy (Figure $2 \mathrm{~g}$ ) appeared mainly in the parallel and anti-parallel directions, showing the signature of a cigar distribution [24,32-34,55]. Such a cigar distribution of electrons with low energy was also observed in previous CDPSs caused by the solar wind entry via a low-latitude boundary layer (LLBL) [56]. 


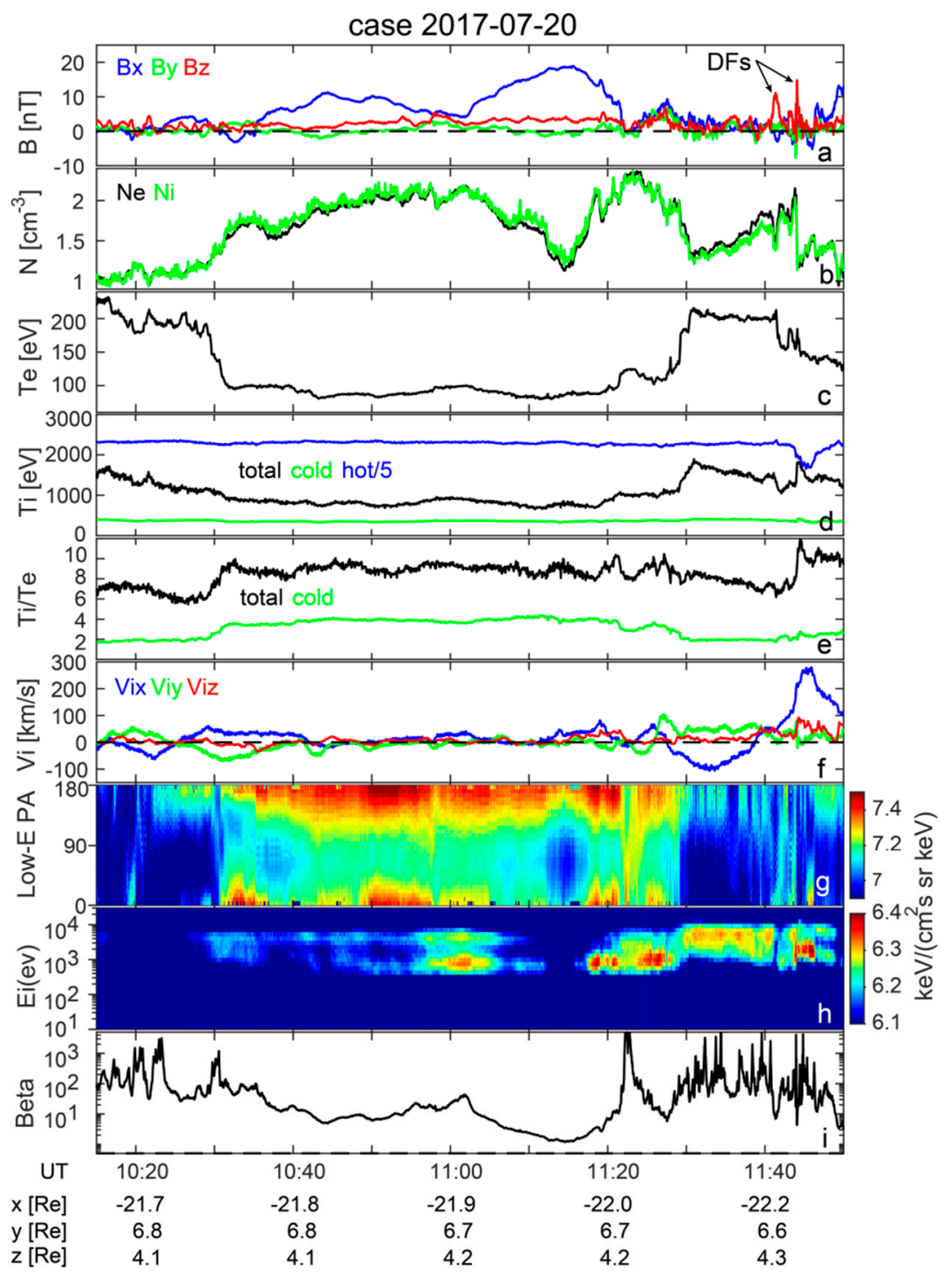

Figure 2. MMS1 observations of a cold and dense plasma sheet (CDPS) on 20 July 2017. (a) Magnetic field $\mathrm{B}_{\mathrm{x}}$ component (blue curve), $\mathrm{B}_{\mathrm{y}}$ component(green curve), and $\mathrm{B}_{\mathrm{z}}$ component(red curve); (b) electron (black curve) and ion (green curve) number density; (c) electron temperature; (d) ion temperature (black), cold ion temperature (green), and hot ion temperature divided by 5 (blue); (e) the ratio of the ion to electron temperature (black) and the ratio of the cold ion to electron temperature (green); (f) ion velocity $\mathrm{V}_{\mathrm{x}}$ component (blue curve), $\mathrm{V}_{\mathrm{y}}$ component (green curve), and $\mathrm{V}_{\mathrm{z}}$ component (red curve); (g) pitch angle distribution of electrons with an energy of 2-200 eV; (h) ion differential energy flux $(0.01-30 \mathrm{keV})$; and (i) plasma $\beta$. The orbit of MMS is presented at the bottom of panel i.

The global MHD model with kinetic test particles [8] showed that the cold ion population originates from the solar wind through LLBL. Previous observations found that the energy of the cold ion population in the CDPS is similar to that of ions in the solar wind [4,5,41]. However, there is no direct comparison of these ion populations between the CDPS and the solar wind.

Figure 3 shows a direct comparison of these ion populations between the CDPS and the solar wind, using the plasma sheet data collected by MMS1 in the fast mode [42] and the solar wind data collected by ARTEMIS P1 in the reduced mode [45]. As can be seen, the CDPS was detected during northward IMF periods $\left(B_{z}>0\right.$; Figure 3a), consistent with previous studies (Wing et al. [12] and therein). The energy of ions in the solar wind (Figure $3 b$ ) is indeed consistent with that of cold ions in the CDPS (Figure 3c), directly demonstrating that these cold ions in the CDPS may originate from the solar wind. To verify our inference, we checked $\mathrm{He}+$ in this CDPS, which comes from the solar wind. 
He+ was observed when the CDPS was detected (Figure 3d), which further proves that these cold ions in the CDPS originate from the solar wind. The distribution of cold ions is intermittent (Figure 3c,d), which may attributable to the spatial discontinuity of cold ions. The solar wind may cross the flank of the bow shock and then enter the plasma sheet.

It has been suggested that the solar wind plasma can enter the plasma sheet via the low-latitude boundary layer (LLBL) during northward IMF periods [3,57]. Thus, the ion number density in the CDPS should be correlated with that in the solar wind. Based on the correlation, we can estimate the duration for the solar wind ion to propagate from the LLBL to the plasma sheet, which is to say we can search for which period the ion number density in the solar wind has the best correlation with ion number density in the CDPS. We perform a cross-correlation analysis between the ion number density in the CDPS and ion number density in the solar wind. The cross-correlation coefficient is defined as follows:

$$
R_{s p, c o e f f}(t)=\left\{\begin{array}{c}
\frac{\sum_{i=1}^{t} N_{s w}(M-t+i) N_{p s}(i)}{\sqrt{\left[\sum_{i=1}^{t} N_{s w}(M-t+i) N_{s w}(M-t+i)\right]\left[\sum_{i=1}^{t} N_{p s}(i) N_{p s}(i)\right]}}, t \leq N \\
\frac{\sum_{i=1}^{N} N_{s w}(M-t+i) N_{p s}(i)}{\sqrt{\left[\sum_{i=1}^{N} N_{s w}(M-t+i) N_{s w}(M-t+i)\right]\left[\sum_{i=1}^{N} N_{p s}(i) N_{p s}(i)\right]}}, N<t \leq M
\end{array}\right.
$$

$N_{s w}, N_{p s}, M, N$, and $t$ represent the ion number density in solar wind, ion number density in CDPS, time scale of $N_{s w}$, time scale of $N_{p s}$, and time lag.

Since the ion data resolution of ARTEMIS ( $4.3 \mathrm{~s}$ resolution) is higher than that of MMS (4.4 s resolution), we perform the linear interpolation to reduce the ARTEMIS resolution. The time-series of the ion number density in the CDPS (10:10:00-11:50:00 UT) slides back along that of the ion number density in the solar wind from the time that the CDPS was detected. During this process, the cross-correlation coefficient first increases and then decreases. The largest cross correlation coefficient $(\sim 0.62)$ occurs at lags $\approx 4.1 \mathrm{~h}$ (Figure $3 \mathrm{e}$ ), indicating that it takes $4.1 \mathrm{~h}$ for ions to propagate from the ARTEMIS location to the plasma sheet. Considering the fact that the solar wind velocity is stable, $(-35060-25] \mathrm{km} / \mathrm{s}$, we can estimate that the duration for ions to propagate from the ARTEMIS location to the LLBL is $\sim 24 \mathrm{~min}$. Therefore, it takes $3.7 \mathrm{~h}$ for ions to propagate from the LLBL to the plasma sheet. The energy of ions in the solar wind $4.1 \mathrm{~h}$ ago (Figure 7e) is still consistent with that of cold ions in the CDPS, suggesting that the results of this cross-correlation analysis are reasonable.

The second event was observed by MMS from 02:10:00 to 05:30:00 UT on 4 August 2017, when MMS spacecrafts were moving from $(-22.589,8.767,5.821) R_{E}$ to $(-22.328,7.805,5.923) R_{E}$ in Geocentric Solar Magnetospheric (GSM) coordinates (see red pentagram in Figure 4), indicating that MMS spacecrafts were located on the duskside of the magnetotail. At the same time, ARTEMIS was moving from $(-48.567,38.941,4.390) R_{E}$ to $(-49.941,38.043,4.257) R_{E}$ in GSM coordinates (see yellow pentagram in Figure 4), indicating that ARTEMIS was located in the solar wind. Figure 5, in the same format as Figure 2, presents an overview of the event. These data were collected by MMS1 in the fast mode [42]. During this period, MMS measured a small magnetic field $B_{x}\left(\left|B_{x}\right|<20 n T\right.$; see blue line in Figure $\left.5 a\right)$, high plasma densities $\left(N \gtrsim 1 \mathrm{~cm}^{-3}\right.$; Figure $\left.5 b\right)$, and a large plasma $\beta(\beta>0.5$; Figure $5 \mathrm{i})$, indicating that it was in the plasma sheet [49]. The plasma density is $3 \sim 10 \mathrm{~cm}^{-3}$ (Figure $5 b$ ), i.e., $10-30$ times the average value of the plasma sheet. In addition, the ion and electron temperatures are $400-800 \mathrm{eV}$ (Figure $5 \mathrm{~d}$ ) and $20-70 \mathrm{eV}$ (Figure 5c), respectively. The ion spectrum features two ion populations with distinctly different energies (Figure $5 \mathrm{~h}$ ), whose cold and hot ion population energies are $0.1-1.2 \mathrm{keV}$ and $6-20 \mathrm{keV}$, respectively. These features are consistent with those in the CDPS [10,51-53]. During the crossing of the CDPS, the temperature of the cold ion populations was $\sim 200 \mathrm{eV}$ (green curve in Figure $2 \mathrm{~d}$ ), while that of the hot ion populations was $\sim 5 \mathrm{keV}$ (blue curve in Figure 2d). As can be seen, the ratios of the ion to electron temperature and cold ion to electron temperature were $\sim 15$ and $\sim 5$, respectively. In addition, these low-energy electrons (Figure $2 \mathrm{~g}$ ) showed the signature of a cigar distribution, which was also observed in previous CDPSs caused by solar wind entry via the low-latitude boundary layer. Figure 6, 
in the same format as Figure 4, shows a direct comparison of these ion populations between the CDPS sheet and the solar wind, using the plasma sheet data collected by MMS1 in the fast mode [42] and the solar wind data collected by ARTEMIS P1 in the reduced mode [45]. As can be seen, the CDPS was detected during northward IMF periods $\left(B_{z}>0\right.$; Figure $\left.6 a\right)$, consistent with previous studies (Wing et al. [12] and therein). The energy of ions in the solar wind (Figure 6b) is indeed consistent with that of cold ions in the CDPS (Figure 6c), directly demonstrating that cold ions in the CDPS originate from solar wind. In addition, $\mathrm{He}^{+}$, mainly from the solar wind, was observed when the CDPS was detected (Figure 6d), which also demonstrates that these cold ions in the CDPS originate from the solar wind. We also performed a cross-correlation analysis on the ion number density between the CDPS and the solar wind. We selected the time-series of the CDPS from 02:10:00 to 05:30:00 UT, sliding it back along that of the ion number density in the solar wind from the time that the CDPS was detected. As can be seen, ARTEMIS is located downstream of MMS, indicating that the ions observed by ARTEMIS cannot propagate toward MMS. However, these upstream cold ions near the LLBL can propagate to the downstream ARTEMIS and can simultaneously leak into the plasma sheet. The time needed for these upstream cold ions near the LLBL to propagate to ARTEMIS is defined as Ta, while the time needed for these upstream cold ions near the LLBL to propagate to the MMS is defined as Tm. Thus, the time lag obtained by the cross-correlation analysis is Tm-Ta. Then, we can obtain the time needed for the upstream cold ions near the LLBL to propagate to MMS by adding $\mathrm{Ta}$ to $\mathrm{Tm}$ - Ta. The largest cross correlation coefficient $(\sim 0.8)$ occurs at lags $\approx 5.7 \mathrm{~h}$ (Figure $6 \mathrm{e})$, namely $\mathrm{Tm}-\mathrm{Ta}=5.7 \mathrm{~h}$. Considering the fact that the solar wind velocity is stable, $(-360600) \mathrm{km} / \mathrm{s}$, we can estimate that the duration needed for ions to propagate from the LLBL to the ARTEMIS location is $\sim 14 \mathrm{~min}(\mathrm{Ta})$. Therefore, it takes $5.9 \mathrm{~h}$ for ions to propagate from the LLBL to the plasma sheet. The energy of ions in the solar wind $5.7 \mathrm{~h}$ ago (Figure 7j) is still consistent with that of cold ions in the CDPS, suggesting that the results of this cross-correlation analysis are reasonable.
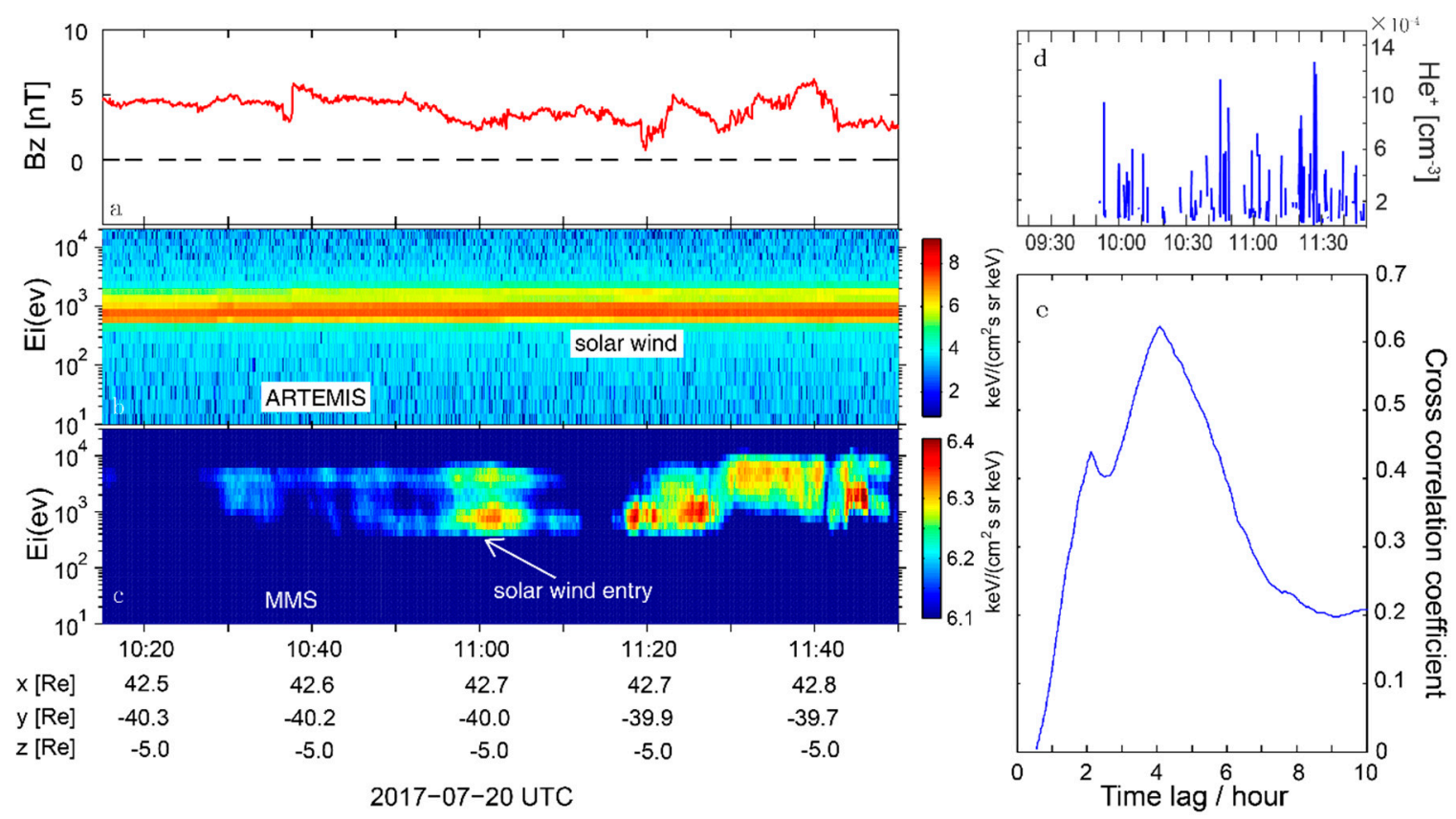

Figure 3. Direct comparison of the ion populations between the CDPS and the solar wind on 20 July 2017. ARTEMIS observations of (a) the Interplanetary Field (IMF) $B_{z}$ component and (b) ion differential energy flux in the solar wind. MMS1 observations of (c) the ion differential energy flux in the CDPS and (d) $\mathrm{He}^{+}$number density. (e) Cross-correlation coefficient of the ion number density between the CDPS and the solar wind. The orbit of ARTEMIS is presented at the bottom of panel c. 


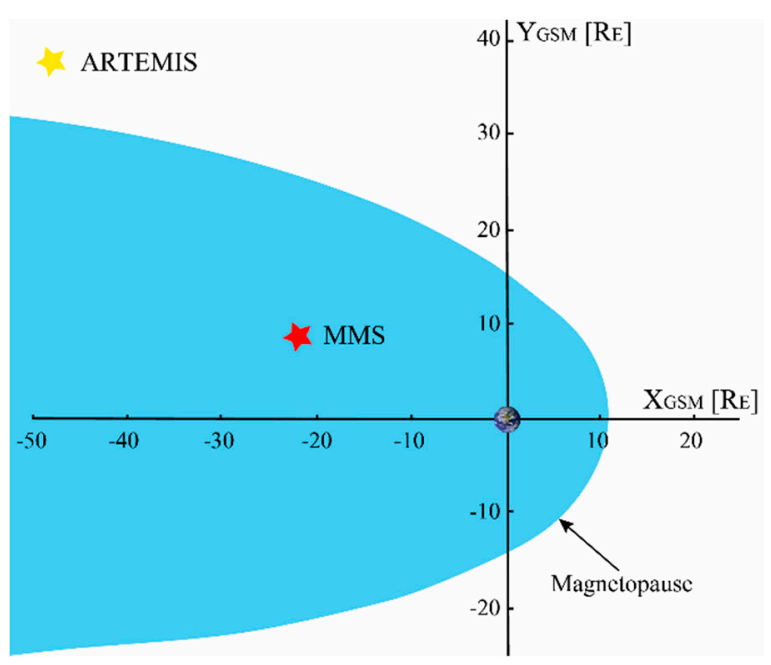

Figure 4. The locations of MMS (denoted by red pentagram) and ARTEMIS (denoted by yellow pentagram) in the GSM coordinates on 4 August 2017.The figure is in the same format as Figure 1.

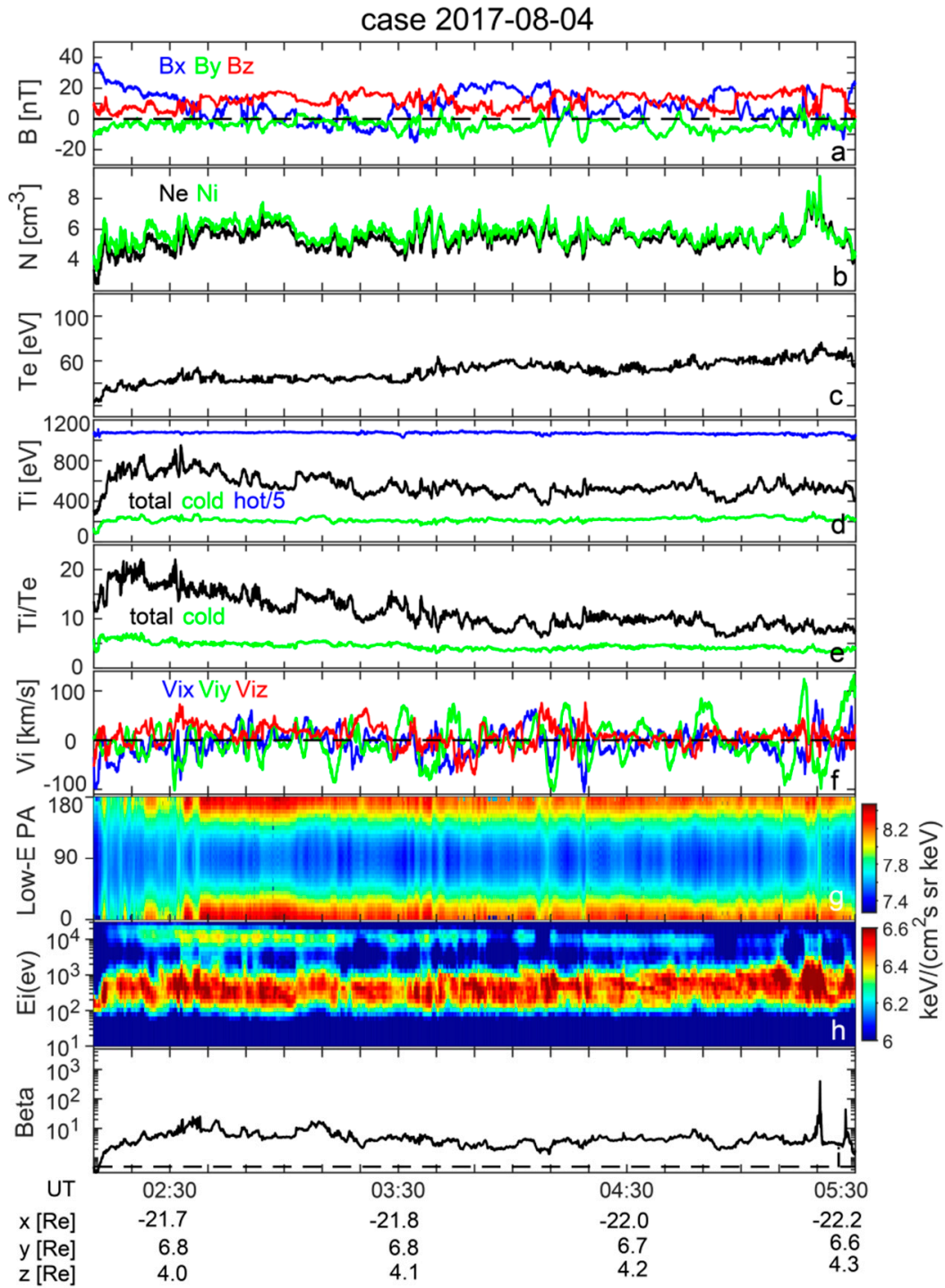

Figure 5. MMS1 observations of a CDPS on 4 August 2017.The figure is in the same format as Figure 2. 

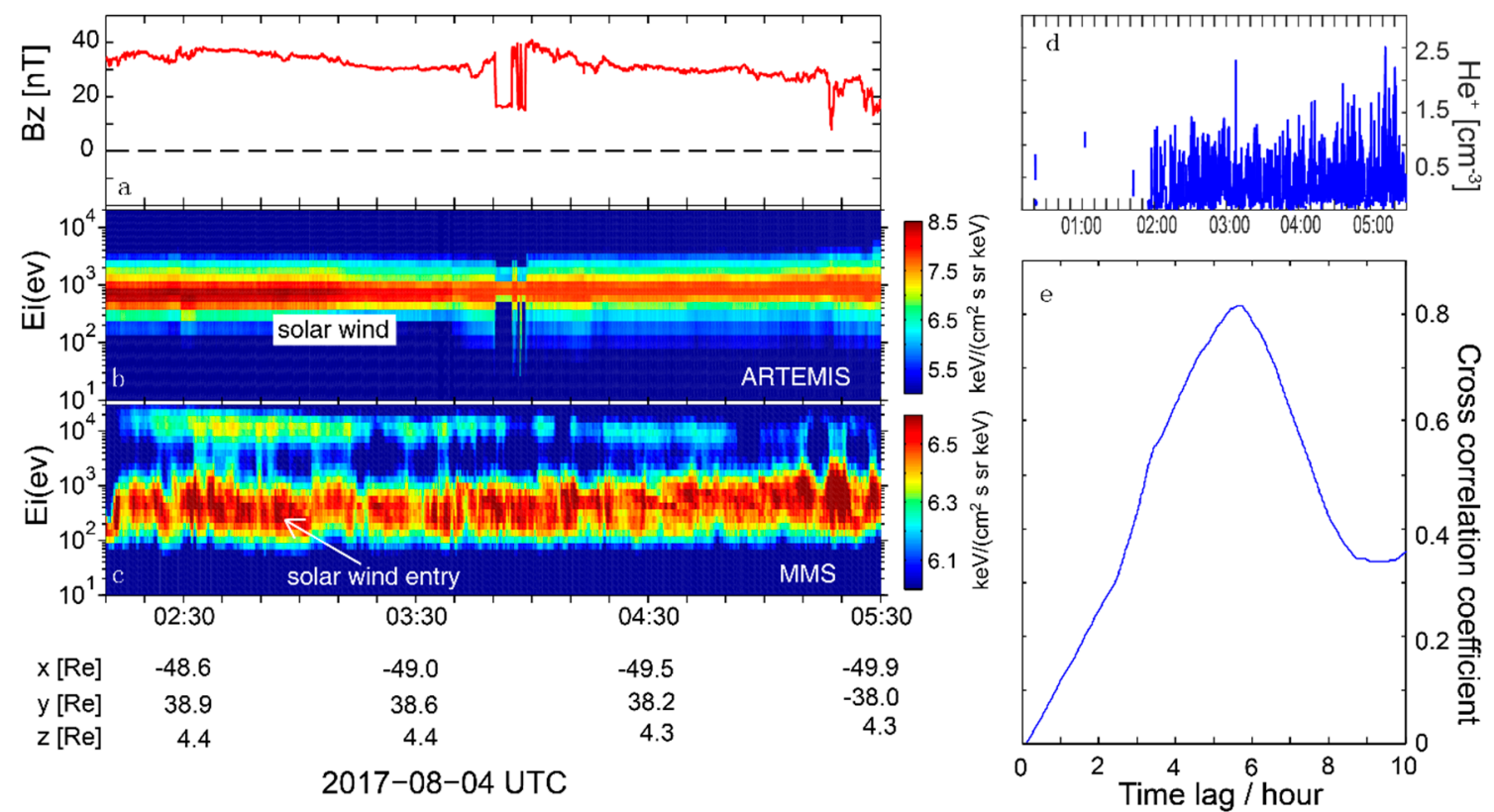

Figure 6. Direct comparison of the ion populations between the CDPS and the solar wind on 4 August 2017. The figure is in the same format as Figure 3.

\section{Summary and Discussion}

In this study, we analyze two cold and dense plasma sheets (CDPSs) via an MMS mission during northward IMF periods, and we find that the energy of cold ion populations in these CDPSs is consistent with that of ion populations observed by the ARTEMIS mission in the solar wind, directly demonstrating that the CDPS is the consequence of the solar wind entry. In addition, $\mathrm{He}^{+}$, mainly from the solar wind, was observed in these CDPSs. In these CDPSs, the plasma density was $\sim 4-30$ times the average plasma sheet value. We performed a cross-correlation analysis of the ion density between the CDPS and the solar wind, and found that it takes 3.7-5.9 h for solar wind ions to enter the plasma sheet. Such coordinated observations confirm the previous speculation based on single-spacecraft measurements.

The path of solar wind ions entering the plasma sheet depends on the IMF conditions. On the one hand, during southward IMF periods, solar wind ions enter the magnetosphere via magnetopause magnetic reconnection [58] and are then convected to the magnetotail. Subsequently, these ions are propagated towards the tail center and then energized and thermalized in the plasma sheet $[59,60]$. On the other hand, during northward IMF periods, there are two major entry mechanisms: (1) the double cusp reconnection, which captures magnetosheath plasma, and (2) the Kelvin-Helmholtz instability, which makes solar wind ions "leak" into the plasma sheet via the low-latitude boundary layer (LLBL) along the flanks of the magnetosphere [42,57].

The global MHD model with kinetic test particles [8] showed that Cusp-entering ions are predominantly deflected toward the dawn-side and are heated, while Flank-entering ions via LLBL are dawn-dusk symmetric and relatively cold. These mechanisms lead to ion populations in the plasma sheet exhibiting a dawn-dusk asymmetry $[8,61,62]$ : these ion populations at the dusk-side exhibit a two-component structure of energy distribution due to the cold Flank-entering ions and the higher-energy subset of Cusp-entering ions that drift from the dawn-side, while the ion populations at the dawn-side exhibit a hotter and broadly peaked energy distribution due to the cold Flank-entering ions and the lower-energy subset of Cusp-entering ions. In these two events, the cold dense plasma sheets were detected at the dusk-side of the plasma sheet during northward IMF periods (Figures 3a and 6a). Thus, the cold component more likely constitutes the flank-entering ions via KHI, while the hot component may constitute the Cusp-entering ions that drift from the dawn-side. 
Li et al. [35] performed MHD simulations on the entry rate of the double cusp reconnection under different solar wind conditions, showing that the entry rate peaked under the following conditions: (1) the IMF magnitude was $10 \mathrm{nT}$, (2) the IMF clock angle was $0^{\circ}$, (3) the ion number density was $6.6 \mathrm{~cm}^{-3}$, (4) the solar wind speed was $500 \mathrm{~km} / \mathrm{s}$, and (5) the dipole tilt angle was $15^{\circ}$. For the first event, we checked the solar wind condition when the IMF was northward $\sim 4 \mathrm{~h}$ ago: (1) the IMF magnitude was $\sim 4 \mathrm{nT}$ (Figure 7a), (2) the IMF clock angle varied from $\sim 80^{\circ}$ to $\sim 0^{\circ}$ (Figure $7 \mathrm{~b}$ ), (3) the ion number density was $\sim 3 \mathrm{~cm}^{-3}$, (4) the solar wind speed was $\sim 358 \mathrm{~km} / \mathrm{s}$ (not shown), and (5) the dipole tilt angle was $\sim 20.36^{\circ}$ (not shown). Such conditions deviate largely from the best conditions presented in Li et al. [35], indicating that the entry rate of the double cusp reconnection was low. For the second event, we checked the solar wind conditions when the IMF was northward $\sim 5.7 \mathrm{~h}$ ago: (1) the IMF magnitude was $\sim 30 \mathrm{nT}$ (Figure 7f), (2) the IMF clock angle was $\sim 55^{\circ}$ (Figure $7 \mathrm{~g}$ ), (3) the ion number density was $\sim 15 \mathrm{~cm}^{-3}$, (4) the solar wind speed was $\sim 365 \mathrm{~km} / \mathrm{s}$ (not shown), and (5) the dipole tilt angle was $\sim 10.02^{\circ}$ (not shown). Such conditions also deviate largely from the best conditions presented in Li et al. [35], indicating that the entry rate of the double cusp reconnection was low. Thus, the cusp reconnection may contribute little to CDPSs. However, the simulation of Li et al. [35] is based on the long-lasting northward IMF. Such a condition is different from that in our events, which were observed shortly after IMF turned from southward to northward. Therefore, we can only obtain a rough estimation of the entry rate.

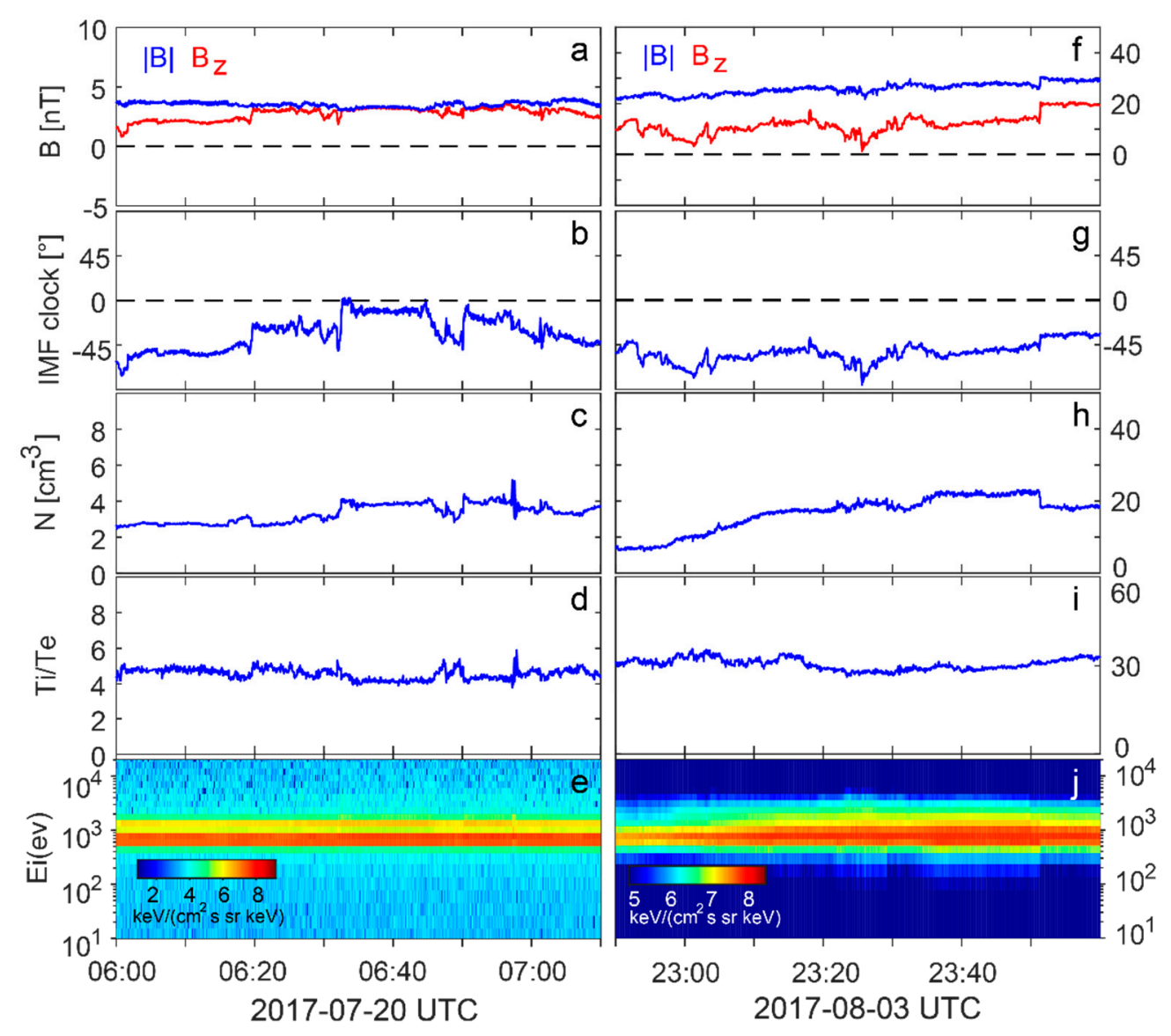

Figure 7. Parameters of the solar wind observed by ARTEMIS. On 20 July 2017: (a)Magnetic field strength (blue) and magnetic field $\mathrm{B}_{\mathrm{z}}$ component (red); (b) Interplanetary magnetic field (IMF) clock angle; (c) ion number density; (d) the ratio of the ion to electron temperature; (e) ion differential energy flux (0.01-30 keV). On 3 August 2017: (f) Magnetic field strength (blue) and magnetic field $B_{\mathrm{Z}}$ component (red); (g) IMF clock angle; (h) ion number density; (i) the ratio of the ion to electron temperature; (j) ion differential energy flux $(0.01-30 \mathrm{keV})$. 
Therefore, these two CDPSs are mainly caused by KHI that occurs at LLBL. The cross-correlation analysis suggests that it takes $3.7-5.9 \mathrm{~h}$ for solar wind ions to enter the plasma sheet through the pathway, which is in agreement with previous studies [10].

Fujimoto et al. [56] presented a CDPS event where cold ion populations originate from the magnetosheath via LLBL. In the CDPS, these low-energy electrons mainly appear in the parallel and anti-parallel directions, showing the signature of a cigar distribution. In our events, one can observe a similar phenomenon as well (see Figures $2 \mathrm{~g}$ and $5 \mathrm{~g}$ ). Wang et al. [41] presented a magnetopause crossing at LLBL and found that the $T_{i} / T_{e}$ was conserved. In our study, however, the $T_{i} / T_{e}$ in the deeper plasma sheet was not the same as that in the solar wind. For the first event, $T_{i} / T_{e}$ in the plasma sheet ( 9) was larger than that in the solar wind ( 4) due to the existence of hotter ions in the plasma sheet, while the ratio of the cold ion to electron temperature in the plasma sheet $(\sim 4)$ was similar to $\mathrm{T}_{\mathrm{i}} / \mathrm{T}_{\mathrm{e}}$ in the solar wind $(\sim 4)$ due to the fact that these cold ions came from the solar wind. For the second event, both $\mathrm{T}_{\mathrm{i}} / \mathrm{T}_{\mathrm{e}}(\sim 15)$ and the cold ion to electron temperature $(\sim 5)$ in the plasma sheet were smaller than $\mathrm{T}_{\mathrm{i}} / \mathrm{T}_{\mathrm{e}}$ in the solar wind ( 30), possibly owing to the turbulent plasma environment in the magnetosheath when the solar wind near the LLBL propagated to the downstream ARTEMIS. Thus, we guess that $\mathrm{T}_{\mathrm{i}} / \mathrm{T}_{\mathrm{e}}$ near the LLBL may be $\sim 5$.

The CDPSs have effects on the dipolarization fronts (DFs) dynamics. The cold and dense plasma can alter the plasma density gradients near the dipolarization fronts $[20,63]$ and thus affect the density-driven instabilities [21,22,64], electric field structure [23], and wave-particle interactions [62] near the DFs. It also possibly affects the growth and decay of the DF. In the first event, MMS detected two DFs (Figure 2a) embedded in an earthward ions flow burst (Figure 2f). Around these two DFs, the plasma number density varied dramatically, suggesting that the plasma density gradients near the DFs may be inconsistent with that near the normal DF. Further analyses of plasma density gradients near these two DFs remain to be conducted in future studies.

Author Contributions: Y.Y. gave the basic idea of the paper. Y.Y. and Z.C. designed the experiments and analysis tools, Y.Y., Z.C., and F.C. performed the experiments, and analyzed the data; Y.Y. and Z.C. participated in discussion and interpretation of the data. Y.Y. wrote the paper. All authors have read and agreed to the published version of the manuscript.

Funding: This research was funded by the National Natural Science Foundation of China (grant no. 41821003 and 41874188).

Acknowledgments: We thank the MMS team and ARTEMIS team for providing the data for this study. MMS data and ARTEMIS data are available at https://lasp.colorado.edu/mms/sdc/public/ and https://cdaweb.sci.gsfc. nasa.gov/index.html/, respectively.

Conflicts of Interest: The authors declare no conflict of interest.

\section{References}

1. Baumjohann, W.; Paschmann, G.; Cattell, C.A. Average plasma properties in the center plasma sheet. J. Geophys. Res. Space Phys. 1989, 94, 6597-6606. [CrossRef]

2. Fairfield, D.H.; Lepping, R.P.; Hones, E.W.; Bame, S.J.; Asbridge, J.R. Simultaneous measurements of magnetotail dynamics by IMP spacecraft. J. Geophys. Res. 1981, 86, 1396-1414. [CrossRef]

3. Fujimoto, M.; Terasawa, T.; Mukai, T.; Saito, Y.; Yamamoto, T.; Kokubun, S. Plasma entry from the flanks of the near-Earth magnetotail: Geotail observations. J. Geophys. Res. 1998, 103, 4391-4408. [CrossRef]

4. Lennartsson, O.W.; Shelley, E.G. Survey of 0.1- to 16-keV/e plasma sheet ion composition. J. Geophys. Res. 1986, 91, 3061-3076. [CrossRef]

5. Lennartsson, W. A scenario for solar wind penetration of earth's magnetotail based on ion composition data from the ISEE 1 spacecraft. J. Geophys. Res. 1992, 97, 19221-19238. [CrossRef]

6. Øieroset, M.; Raeder, J.; Phan, T.D.; Wing, S.; McFadden, J.P.; Li, W.; Fujimoto, M.; Rème, H.; Balogh, A. Global cooling and densification of the plasma sheet during an extended period of purely northward IMF on October 22-24, 2003. Geophys. Res. Lett. 2005, 32, L12S07. [CrossRef] 
7. Stenuit, H.; Fujimoto, M.; Fuselier, S.A.; Sauvaud, J.-A.; Wing, S.; Fedorov, A.; Budnik, E.; Savin, S.P.; Trattner, K.J.; Angelopoulos, V.; et al. Multi-spacecraft study ion the dynamics of the dusk-flank magnetosphere under northward IMF: January 10-11, 1997. J. Geophys. Res. 2002, 107, 1333. [CrossRef]

8. Sorathia, K.; Merkin, V.G.; Ukhorskiy, A.Y.; Allen, R.C.; Nykyri, K.; Wing, S. Solar wind ion entry into the magnetosphere during northward IMF. J. Geophys. Res. Space Phys. 2019, 124, 5461-5481. [CrossRef]

9. Thomsen, M.F.; Borovsky, J.E.; Skoug, R.M.; Smith, C.W. Delivery of cold, dense plasma sheet material into the near-Earth region. J. Geophys. Res. 2003, 108, 1151. [CrossRef]

10. Terasawa, T.; Fujimoto, M.; Mukai, T.; Shinohara, I.; Lepping, R.P. Solar wind control of density and temperature in the near-Earth plasma sheet: WIND/GEOTAIL collaboration. Geophys. Res. Lett. 1997, 24, 935-938. [CrossRef]

11. Wing, S.; Newell, P.T. 2D plasma sheet ion density and temperature profiles for northward and southward IMF. Geophys. Res. Lett. 2002, 29, 21-1-21-4. [CrossRef]

12. Wing, S.; Johnson, J.R.; Chaston, C.C.; Echim, M.; Escoubet, C.P.; Lavraud, B.; Lemon, C.; Nykyri, K.; Otto, A.; Raeder, J.; et al. Review of Solar Wind Entry into and Transport within the Plasma Sheet. Space Sci. Rev. 2014, 184, 33-86. [CrossRef]

13. Borovsky, J.E.; Thomsen, M.F.; McComas, D.J. The superdense plasma sheet: Plasmaspheric origin, solar wind origin, or ionospheric origin? J. Geophys. Res. 1997, 102, 22089-22097. [CrossRef]

14. Lavraud, B.; Thomsen, M.F.; Borovsky, J.E.; Denton, M.H.; Pulkkinen, T.I. Magnetosphere preconditioning under northward IMF: Evidence from the study of coronal mass ejection and corotating interaction region geoeffectiveness. J. Geophys. Res. 2006, 111, A09208. [CrossRef]

15. Fu, H.S.; Khotyaintsev, Y.V.; Vaivads, A.; André, M.; Huang, S.Y. Occurrence rate of earthward-propagating dipolarization fronts. Geophys. Res. Lett. 2012, 39, L10101. [CrossRef]

16. Xu, Y.; Fu, H.S.; Norgren, C.; Hwang, K.J.; Liu, C.M. Formation of dipolarization fronts after current sheet thinning. Phys. Plasmas 2018, 25, 072123. [CrossRef]

17. Yao, Z.; Sun, W.J.; Fu, S.Y.; Pu, Z.Y.; Liu, J.; Angelopoulos, V.; Zhang, X.J.; Chu, X.N.; Shi, Q.Q.; Guo, R.L.; et al. Current structures associated with depolarization fronts. J. Geophys. Res. Space Phys. 2013, 118, 6980-6985. [CrossRef]

18. Toledo-Redondo, S.; André, M.; Khotyaintsev, Y.V.; Vaivads, A.; Walsh, A.; Li, W.; Graham, D.B.; Lavraud, B.; Masson, A.; Aunai, N.; et al. Cold ion demagnetization near the X-line of magnetic reconnection. Geophys. Res. Lett. 2016, 43, 6759-6767. [CrossRef]

19. Wang, J.; Cao, J.B.; Fu, H.S.; Liu, W.L.; Lu, S. Enhancement of oxygen in the magnetic island associated with dipolarization fronts. J. Geophys. Res. Space Phys. 2017, 122, 185-193. [CrossRef]

20. Xu, Y.; Fu, H.S.; Norgren, C.; Toledo-Redondo, S.; Liu, C.M.; Dong, X.C. Ionospheric cold ions detected by MMS behind dipolarization fronts. Geophys. Res. Lett. 2019, 46, 7883-7892. [CrossRef]

21. Chen, Z.Z.; Fu, H.S.; Liu, C.M.; Wang, T.Y.; Ergun, R.E.; Cozzani, G.; Huang, S.Y.; Khotyaintsev, Y.V.; Le Contel, O.; Giles, B.L.; et al. Electron-driven dissipation in a tailward flow burst. Geophys. Res. Lett. 2019, 46, 5698-5706. [CrossRef]

22. Liu, C.M.; Fu, H.S.; Vaivads, A.; Khotyaintsev, Y.V.; Gershman, D.J.; Hwang, K.J.; Chen, Z.Z.; Cao, D.; Xu, Y.; Yang, J.; et al. Electron jet detected by MMS at dipolarization front. Geophys. Res. Lett. 2018, 45, 556-564. [CrossRef]

23. Fu, H.S.; Khotyaintsev, Y.V.; Vaivads, A.; André, M.; Huang, S.Y. Electric structure of depolarization front at sub-proton scale. Geophys. Res. Lett. 2012, 39, L06105. [CrossRef]

24. Fu, H.S.; Khotyaintsev, Y.V.; André, M.; Vaivads, A. Fermi and betatron acceleration of suprathermal electrons behind depolarization fronts. Geophys. Res. Lett. 2011, 38, L16104. [CrossRef]

25. Fu, H.S.; Khotyaintsev, Y.V.; Vaivads, A.; Retinò, A.; André, M. Energetic electron acceleration by unsteady magnetic reconnection. Nat. Phys. 2013, 9, 426-430. [CrossRef]

26. Fu, H.S.; Cao, J.B.; Khotyaintsev, Y.V.; Sitnov, M.I.; Runov, A.; Fu, S.Y.; Hamrin, M.; André, M.; Retinò, A.; Ma, Y.D.; et al. Dipolarization fronts as a consequence of transient reconnection: In situ evidence. Geophys. Res. Lett. 2013, 40, 6023-6027. [CrossRef]

27. Fu, H.S.; Xu, Y.; Vaivads, A.; Khotyaintsev, Y.V. Super-efficient Electron Acceleration by an Isolated Magnetic Reconnection. Astrophys. J. Lett. 2019, 870, L22. [CrossRef]

28. Liu, C.M.; Fu, H.S.; Xu, Y.; Wang, T.Y.; Cao, J.B.; Sun, X.G.; Yao, Z.H. Suprathermal electron acceleration inthe near-Earth flow rebounce region. J. Geophys. Res. Space Phys. 2017, 122, 594-604. [CrossRef] 
29. Liu, C.M.; Liu, Y.Y.; Xu, Y.; Zhao, M.J. Betatron Cooling of Suprathermal Electrons in the Terrestrial Magnetotail. Astrophys. J. 2018, 866, 93. [CrossRef]

30. Wu, M.; Lu, Q.; Volwerk, M.; Nakamura, R.; Zhang, T. Electron acceleration behind a wavy dipolarization front. Astrophys. Space Sci. 2018, 363, 22. [CrossRef]

31. Xu, Y.; Fu, H.S.; Liu, C.M.; Wang, T.Y. Electron acceleration by dipolarization fronts and magnetic reconnection: A quantitative comparison. Astrophys. J. 2018, 853, 11. [CrossRef]

32. Fu, H.S.; Khotyaintsev, Y.V.; Vaivads, A.; André, M.; Sergeev, V.A.; Huang, S.Y.; Kronberg, E.A.; Daly, P.W. Pitch angle distribution of suprathermal electrons behind dipolarization fronts: A statistical overview. J. Geophys. Res. 2012, 117, A12221. [CrossRef]

33. Liu, C.M.; Fu, H.S.; Cao, J.B.; Xu, Y.; Yu, Y.Q.; Kronberg, E.A.; Daly, P.W. Rapid pitch angle evolution of suprathermal electrons behind dipolarization fronts. Geophys. Res. Lett. 2017, 44, 10116-10124. [CrossRef]

34. Liu, C.M.; Fu, H.S.; Xu, Y.; Cao, J.B.; Liu, W.L. Explaining the rolling-pin distribution of suprathermal electrons behind depolarization fronts. Geophys. Res. Lett. 2017, 44, 6492-6499. [CrossRef]

35. Li, W.; Raeder, J.; Thomsen, M.F.; Lavraud, B. Solar wind plasma entry into the magnetosphere under northward IMF conditions. J. Geophys. Res. 2008, 113, A04204. [CrossRef]

36. Lavraud, B.; Denton, M.H.; Thomsen, M.F.; Borovsky, J.E.; Friedel, R.H.W. Superposed epoch analysis of dense plasma access to geosynchronous orbit. Ann. Geophys. 2005, 23, 2519-2529. [CrossRef]

37. Øieroset, M.; Yamauchi, M.; Liszka, L.; Hultqvist, B. Energetic ion outflow from the dayside ionosphere: Categorization, classification, and statistical study. J. Geophys. Res. 1999, 104, 24915-24928. [CrossRef]

38. Yau, A.W.; Shelley, E.G.; Peterson, W.K.; Lenchyshyn, L. Energetic auroral and polar ion outflow at DE 1 altitudes: Magnitude, composition, magnetic activity dependence, and long-term variations. J. Geophys. Res. 1985, 90, 8417. [CrossRef]

39. Fuselier, S.A.; Elphic, R.C.; Gosling, J.T. Composition measurements in the dusk flank magnetopause. J. Geophys. Res. 1999, 104, 4515-4522. [CrossRef]

40. Reme, H.; Aoustin, C.; Bosqued, J.M.; Dandouras, I.; Lavraud, B.; Sauvaud, J.A.; Barthe, A.; Bouyssou, J.; Camus, T.; Coeur-Joly, O.; et al. First multispacer craft ion measurements in and near the Earth's magnetosphere with identical Cluster ion spectrometry (CIS) experiments. Ann. Geophys. 2001, 19, 1303-1354. [CrossRef]

41. Wang, C.-P.; Gkioulidou, M.; Lyons, L.R.; Angelopoulos, V. Spatial distributions of the ion to electron temperature ratio in the magnetosheath and plasma sheet. J. Geophys. Res. 2012, 117, A08215. [CrossRef]

42. Burch, J.L.; Moore, T.E.; Torbert, R.B.; Giles, B.L. Magnetospheric Multiscale overview and science objectives. Space Sci. Rev. 2016, 199, 5-21. [CrossRef]

43. Russell, C.T.; Anderson, B.J.; Baumjohann, W.; Bromund, K.R.; Dearborn, D.; Fischer, D.; Le, G.; Leinweber, H.K.; Leneman, D.; Magnes, W.; et al. The magnetospheric multiscale magnetometers. Space Sci. Rev. 2014, 199, 189-256. [CrossRef]

44. Pollock, C.; Moore, T.; Jacques, A.; Burch, J.; Gliese, U.; Saito, Y.; Omoto, T.; Avanov, L.; Barrie, A.; Coffey, V.; et al. Fast plasma investigation for magnetospheric multiscale. Space Sci. Rev. 2016, 199, 331-406. [CrossRef]

45. Angelopoulos, V. The ARTEMIS mission. Space Sci. Rev. 2011, 165, 3-25. [CrossRef]

46. Auster, H.U.; Glassmeier, K.H.; Magnes, W.; Aydogar, O.; Baumjohann, W.; Constantinescu, D.; Fischer, D.; Fornacon, K.H.; Georgescu, E.; Harvey, P.; et al. The THEMIS fluxgate magnetometer. Space Sci. Rev. 2008, 141, 235-264. [CrossRef]

47. McFadden, J.P.; Carlson, C.W.; Larson, D.; Ludlam, M.; Abiad, R.; Elliott, B.; Turin, P.; Marckwordt, M.; Angelopoulos, V. The THEMIS ESA plasma instrument and in-flight calibration. Space Sci. Rev. 2008, 141, 277. [CrossRef]

48. Sibeck, D.G. A model for the transient magnetospheric response to sudden solar wind dynamic pressure variations. J. Geophys. Res. 1990, 95, 3755-3771. [CrossRef]

49. Cao, J.B.; Ma, Y.D.; Parks, G.; Reme, H.; Dandouras, I.; Nakamura, R.; Zhang, T.L.; Zong, Q.; Lucek, E.; Carr, C.M.; et al. Joint observations by Cluster satellites of bursty bulk flows in the magnetotail. J. Geophys. Res. 2006, 111, A04206. [CrossRef]

50. Huang, S.Y.; Fu, H.S.; Vaivads, A.; Yuan, Z.G.; Pang, Y.; Zhou, M.; Khotyaintsev, Y.V.; Deng, X.H.; André, M.; Zhang, L.; et al. Dawn-dusk scale of dipolarization front in the Earth's magnetotail: Multi-Cases study. Astrophys. Space Sci. 2015, 357, 22. [CrossRef] 
51. Fujimoto, M.; Mukai, T.; Matsuoka, A.; Saito, Y.; Hayakawa, H.; Kokubun, S.; Lepping, R.P. Multipoint observations of cold-dense plasma sheet and its relation with tail-LLBL. Adv. Space Res. 2000, 25, 1607-1616. [CrossRef]

52. Fujimoto, M.; Mukai, T.; Kokubun, S. Cold-dense plasma sheet and hot-dense ions in the inner-magnetosphere. Adv. Space Res. 2002, 30, 2279-2288. [CrossRef]

53. Hasegawa, H.; Fujimoto, M.; Maezawa, K.; Saito, Y.; Mukai, T. Geotail observations of the dayside outer boundary region interplanetary magnetic field control and dawn-dusk asymmetry. J. Geophys. Res. 2003, 108, 1065. [CrossRef]

54. Li, W.; Raeder, J.; Thomsen, M.F.; Lavraud, B.; Lü, L.-Z.; Liang, E.-W. The formation of superdense plasma sheet in association with the IMF turning from northward to southward. J. Geophys. Res. Space Phys. 2018, 122, 2936-2955. [CrossRef]

55. Zhao, M.J.; Fu, H.S.; Liu, C.M.; Chen, Z.Z.; Xu, Y.; Giles, B.L.; Burch, J.L. Energy range of electron rolling pin distribution behind dipolarization front. Geophys. Res. Lett. 2019, 46, 2390-2398. [CrossRef]

56. Fujimoto, M.; Terasawa, T.; Mukai, T. The Cold-dense plasma sheet: A Geotail Perspective. Space Sci. Rev. 1997, 80, 325-339. [CrossRef]

57. Hasegawa, H.; Fujimoto, M.; Phan, T.D.; Re'me, H.; Balogh, A.; Dunlop, M.W.; Hashimoto, C.; TanDokoro, R. Transport of solar wind into Earth's magnetosphere through rolled-up Kelvin-Helmholtz vortices. Nature 2004, 430, 755. [CrossRef]

58. Burch, J.L.; Torbert, R.B.; Phan, T.D.; Chen, L.J.; Moore, T.E.; Ergun, R.E.; Eastwood, J.P.; Gershman, D.J.; Cassak, P.A.; Argall, M.R.; et al. Electron-scale measurements of magnetic reconnection in space. Science 2016, 352, aaf2939. [CrossRef]

59. Speiser, T.W. Particle trajectories in model current sheets: 1. Analytical solutions. J. Geophys. Res. 1965, 70, 4219-4226. [CrossRef]

60. Torbert, R.B.; Burch, J.L.; Phan, T.D.; Hesse, M.; Argall, M.R.; Shuster, J.; Ergun, R.E.; Alm, L.; Nakamura, R.; Genestreti, K.J.; et al. Electron-scale dynamics of the diffusion region during symmetric magnetic reconnection in space. Science 2018, 362, 1391-1395. [CrossRef]

61. Haaland, S.; Lybekk, B.; Maes, L.; Laundal, K.; Pedersen, A.; Tenfjord, P.; Ohma, A.; Østgaard, N.; Reistad, J.; Snekvik, K. North south asymmetries in cold plasma density in the magnetotail lobes: Cluster observations. J. Geophys. Res. Space Phys. 2017, 122, 136-149. [CrossRef]

62. Breuillard, H.; Le Contel, O.; Retino, A.; Chasapis, A.; Chust, T.; Mirioni, L.; Graham, D.B.; Wilder, F.D.; Cohen, I.; Vaivads, A.; et al. Multispacecraft analysis of dipolarization fronts and associated whistler wave emissions using MMS data. Geophys. Res. Lett. 2016, 43, 7279-7286. [CrossRef]

63. Liu, C.M.; Fu, H.S.; Xu, Y.; Khotyaintsev, Y.V.; Burch, J.L.; Ergun, R.E.; Gershman, D.G.; Torbert, R.B. Electron-scale measurements of dipolarization front. Geophys. Res. Lett. 2018, 45, 4628-4638. [CrossRef]

64. Chen, Z.Z.; Wang, T.Y.; Yu, Y.; Chen, F. Relationship between Current Filaments and Turbulence during a Turbulent Reconnection. Astrophys. J. Lett. 2020, 888, L16. [CrossRef]

(C) 2020 by the authors. Licensee MDPI, Basel, Switzerland. This article is an open access article distributed under the terms and conditions of the Creative Commons Attribution (CC BY) license (http://creativecommons.org/licenses/by/4.0/). 